\title{
Enhanced Autophagy of Adipose-Derived Stem Cells Grown on Chitosan Substrates
}

\author{
Ching-Ming Yang, ${ }^{1}$ Yen-Jang Huang, ${ }^{1}$ and Shan-hui $\mathrm{Hsu}^{1,2, *}$
}

\begin{abstract}
Autophagy is an important protein quality control mechanism for cells under stress conditions to promote cell survival. Modulation of autophagy on biomaterial substrates is rarely reported. In this study, the autophagy of adipose-derived stem cells (ADSCS) cultured on chitosan (CS) substrates was examined. Compared to the traditional monolayer culture, ADSCs cultured on CS substrates showed spheroid formation as well as a prolonged upregulation of autophagosomal marker-microtubule-associated protein 1 light chain 3 (LC3) II protein expression. In addition, the green fluorescent protein tagged-LC3 (GFP-LC3) expressing ADSCs also revealed more GFPLC3 puncta on CS substrates. The enhanced autophagy on CS substrates was associated with $\mathrm{Ca}^{2+}$, while ethylene glycol tetraacetic acid (EGTA), a $\mathrm{Ca}^{2+}$ chelator, repressed the autophagy in a dose-dependent manner. Moreover, ADSC spheroids on CS substrates demonstrated a higher survival rate and autophagy response upon $\mathrm{H}_{2} \mathrm{O}_{2}$ treatment. The upstream components of autophagy signal pathway-UNC51-like kinase 1 (UIk1), autophagy-related protein 13 (Atg13), and autophagy/beclin-1 regulator 1 (Ambra1) genes were more highly expressed in ADSC spheroids before and after adding $\mathrm{H}_{2} \mathrm{O}_{2}$ than those in the conventional culture. EGTA also decreased the cell viability and autophagy-associated gene expression for ADSC spheroids on CS substrates after $\mathrm{H}_{2} \mathrm{O}_{2}$ treatment. Therefore, we suggest that three-dimensional (3D) cell culture on CS may confer ADSCs the ability to increase the autophagic flux in response to stimulations in a $\mathrm{Ca}^{2+}$-dependent manner.
\end{abstract}

Key words: autophagy; mesenchymal stem cells; oxidative stress; spheroid

\section{Introduction}

Autophagy is a conserved catabolic mechanism for degradation of nonessential or dysfunctional cellular organelles and proteins. ${ }^{1,2}$ Upon induction, the Ulk1 protein kinase complex (Ulk1, Atg13, FIP200, and Atg101) initiates autophagosome formation ${ }^{3}$ and the autophagy/beclin-1 regulator 1 (Ambra1) enhances Ulk1 kinase activity. ${ }^{4}$ Microtubule- associated protein 1 light chain 3-II (LC3-II) localized in the doublemembranes of autophagosome is considered a proper marker to monitor autophagy. ${ }^{5}$ Besides, cytosolic $\mathrm{Ca}^{2+}$ is important for autophagy induction. ${ }^{6,7}$

Mesenchymal stem cells (MSCs) from different adult tissues have recently become a potential cell source for cell therapy because they can differentiate into a variety of cell types. ${ }^{8}$ The environmental conditions of host tissues, however, may not be suitable for MSC growth (e.g., inflammation, hypoxia, oxidative stress, or lack of nutrients). The poor cell viability may further lead to the limited therapeutic efficacy. ${ }^{9}$ Recent works have shown that autophagy protects the bone marrowderived MSCs from apoptosis under hypoxia and serum deprivation. ${ }^{10-12}$

Chitosan (CS) is a polymer obtained from deacetylation of chitin, a nitrogen-containing polysaccharide abundant in nature. The thin membranes made of CS can facilitate cell-cell interaction and induce the selfassembly of MSCs to form three-dimensional (3D)

\footnotetext{
${ }^{1}$ Institute of Polymer Science and Engineering and ${ }^{2}$ Research Center for Developmental Biology and Regenerative Medicine, National Taiwan University, Taipei, Taiwan.

*Address correspondence to: Shan-hui Hsu, PhD, Institute of Polymer Science and Engineering, National Taiwan University, No. 1, Sec. 4 Roosevelt Road, Taipei 10617, Taiwan, ROC, E-mail: shhsu@ntu.edu.tw
}

(C) Ching-Ming Yang et al. 2015; Published by Mary Ann Liebert, Inc. This Open Access article is distributed under the terms of the Creative Commons License (http://creativecommons.org/licenses/by/4.0), which permits unrestricted use, distribution, and reproduction in any medium, provided the original work is properly credited. 
spheroids on the membranes. ${ }^{13}$ These $3 \mathrm{D}$ spheroids express a greater level of stemness marker genes (Oct4, Sox2, and Nanog) and have higher differentiation and engrafting potentials. ${ }^{14,15}$ CS-derived MSC spheroids showed higher cell survival rates in an inflammatory milieu of a sciatic nerve gap ${ }^{16}$ or an infarcted myocardium in rats. ${ }^{17}$ The enhanced cell survival may suggest a protection mechanism from apoptosis.

The purpose of this study is to investigate the regulation of autophagy in adipose-derived stem cells (ADSCs) grown on CS substrates. Here, we demonstrated that culturing on CS substrates increased autophagy in ADSCs and this process required $\mathrm{Ca}^{2+}$. Finally, we suggested that enhanced autophagy may contribute to the cell survival under oxidative stress and nutrient starvation in CS-derived ADSC spheroids.

\section{Materials and Methods}

Cell culture and transfection

All procedures followed the ethics guidelines and were approved by the Animal Care and Use Committee of the University. ADSCs were isolated from the adipose tissue of Sprague-Dawley rats (body weight from 250 to $500 \mathrm{~g}){ }^{13}$ ADSCs were cultured in Dulbecco's modified Eagle's medium-low glucose/F12 (1:1) supplemented with $10 \%$ fetal bovine serum (FBS), $100 \mu \mathrm{g} /$ $\mathrm{ml}$ streptomycin, and $100 \mathrm{U} / \mathrm{ml}$ penicillin (all from Gibco) at $37^{\circ} \mathrm{C}$ in a $5 \% \mathrm{CO}_{2}$ atmosphere. Cells of the third to the fifth passages were used in this study. Rat LC3 cDNA was inserted to pEGFP-C1 vector (Clontech) to create a green fluorescent protein tagged-LC3 protein expressing vector. ${ }^{5}$ ADSCs were seeded in a 6 -well culture plate for $24 \mathrm{~h}$ before transfection. Two micrograms of GFP-LC3 plasmids was transfected into ADSCs using the $\mathrm{K} 2{ }^{\circledR}$ Transfection System (Biontex) according to the manufacturer's instructions.

Preparation of CS substrates and spheroid formation To prepare 1\% CS solution, CS powder (Sigma; molecular weight $510 \mathrm{kDa}$ and degree of deacetylation 77\%) was dissolved and stirred in 1\% aqueous acetic acid solution at room temperature for $16 \mathrm{~h}$. After filtration by a $100 \mu \mathrm{m}$ mesh, the $1 \%$ CS solution was casted on a 24 -well tissue culture plate $(300 \mu \mathrm{l} /$ well $)$ or 6 -well tissue culture plate $(1.5 \mathrm{ml} /$ well $)$ and air-dried in a laminar cabinet for $24 \mathrm{~h}$. Then $0.5 \mathrm{~N} \mathrm{NaOH}$ in $75 \%$ ethanol was added to the CS substrates for $5 \mathrm{~min}$ and washed with distilled water for three times. For spheroid formation, $5 \times 10^{4}$ or $1 \times 10^{4}$ cells were seeded in each well of the CS-coated 24- or 96-well tissue culture plate.

$\mathrm{H}_{2} \mathrm{O}_{2}$ treatment and WST-1 assay

ADSCs $\left(1 \times 10^{4}\right)$ were seeded in the blank culture well (tissue culture polystyrene, TCPS) or CS-coated 96well culture plate. Cells were cultured for $24 \mathrm{~h}$ on TCPS or $72 \mathrm{~h}$ on CS substrates. The medium was replaced in two groups for ADSCs grown on TCPS: a control group, and a $\mathrm{H}_{2} \mathrm{O}_{2}$-treated group (incubation with $600 \mu \mathrm{M} \mathrm{H}_{2} \mathrm{O}_{2}$ in $2 \% \mathrm{FBS}$ medium). The medium was replaced in four groups for ADSCs grown on CS substrates: a control group, a $\mathrm{H}_{2} \mathrm{O}_{2}$ treated-group (incubation with $600 \mu \mathrm{M} \mathrm{H}_{2} \mathrm{O}_{2}$ in $2 \%$ FBS medium), a $\mathrm{H}_{2} \mathrm{O}_{2}$ + ethylene glycol tetraacetic acid (EGTA)treated group (incubation with $600 \mu \mathrm{M} \mathrm{H} \mathrm{H}_{2} \mathrm{O}_{2}$ and $2 \mathrm{mM}$ EGTA in $2 \%$ FBS medium); and an EGTAtreated group (incubation with $2 \mathrm{mM}$ EGTA in $2 \%$ FBS medium). After $2 \mathrm{~h}$ incubation, cell viability was detected by the cell proliferation reagent WST1 kit (Roche Applied Science) according to the manufacturer's instructions.

\section{Western blots analysis}

ADSCs were seeded on TCPS or CS substrates at a density of $2.5 \times 10^{5}$ cells per well in a 6 -well culture plate and cultured for $0,2,4,8,16,24$, and $48 \mathrm{~h}$. ADSCs were harvested at the indicated times. For $\mathrm{H}_{2} \mathrm{O}_{2}$ treatment, ADSCs were cultured for $24 \mathrm{~h}$ on TCPS or $72 \mathrm{~h}$ on CS substrates. After $2 \mathrm{~h}$ incubation, ADSCs were harvested. Cells were lysed in lysis buffer containing $20 \mathrm{mM}$ Hepes (pH 7.5), $420 \mathrm{mM} \mathrm{NaCl}, 1.5 \mathrm{mM}$ $\mathrm{MgCl} 2,0.1 \% \mathrm{NP}-40$, and protease inhibitor cocktail (Sigma). Proteins were separated by 15\% SDS-PAGE and the endogenous LC3 proteins were detected by rabbit polyclonal anti-LC3 antibody (Genetex). For internal control, GAPDH proteins were detected by rabbit monoclonal anti-GAPDH antibody (Cell Signaling). The intensities of protein bands were quantified by Labwork software (UVP).

RNA extraction and quantitative RT-PCR analysis ADSCs were seeded in the TCPS or CS substrates at a density of $5 \times 10^{4}$ cells per well in a 24 -well culture plate and were cultured $24 \mathrm{~h}$ for TCPS or $72 \mathrm{~h}$ for CS substrates. After $2 \mathrm{~h}$ incubation with $\mathrm{H}_{2} \mathrm{O}_{2}$, total RNAs were isolated with Trizol reagent (Invitrogen) and cDNA was synthesized using the RevertAid First 
Strand cDNA Synthesis Kit (MBI Fermentas) according to the manufacturer's instruction. RT-PCR was performed with DyNAmo Flash SYBR Green qPCR Kit (Finnzymes) on a Chromo 4 PTC200 Thermal Cycler (MJ Research). The primers used were Ulk1 forward 5'- TGGAGAACCTAGCCAGCAGT-3' and reverse $5^{\prime}$-GTGCTTCACACACGACGACT-3'; Atg13 forward $5^{\prime}$-AGACCAAGCAAGTCGAAGGA- $3^{\prime}$ and reverse $5^{\prime}$ - CCTTTGGGAGATGATGGCTA-3'; Ambra1 forward $5^{\prime}$-GCAGCTTTCATCCCGAGTAG-3' and reverse $5^{\prime}$-AAGACCTGGGCTACCATGTG-3'; and GAPDH forward $5^{\prime}$ - AGGTCGGTGTGAACGGAT TTG- $3^{\prime}$ and reverse $5^{\prime}$-GGGGTCGTTGATGGCAACA$3^{\prime}$. The relative quantification in gene expression was determined using the $2-\Delta \Delta$-CT method. ${ }^{18}$ Using this method, the fold of changes in gene expression normalized to the GAPDH gene was obtained relative to TCPS.

\section{Immunocytochemistry}

After transfection with GFP-LC3 plasmids for $24 \mathrm{~h}$, ADSCs were recovered for another $24 \mathrm{~h}$ before seeding on CS substrates. After $24 \mathrm{~h}$ the spheroids were then carefully collected and washed with PBS. The spheroids were trypsinized into single cells and seeded on a $1 \%$ gelatin-coated cover slide for $4 \mathrm{~h}$. After washing with PBS and fixation in $4 \%$ paraformaldehyde at room temperature for $10 \mathrm{~min}$, and two washes with $1 \%$ Tween/PBS, the slide was mounted by $90 \%$ glycerol (Merk). Puncta of GFP-LC3 were analyzed using a fluorescence microscope.

\section{Statistical analysis}

Numerical values were expressed as the mean \pm standard deviation (SD). Differences between two groups were assessed by unpaired two-tailed $t$-tests. Results involving more than two groups were assessed by oneway ANOVA and Tukey's multiple comparison test. A $p$-value of less than 0.05 was considered to be statistically significant. Independent experiments were performed for each type of experiments.

\section{Results}

Induction of autophagy in ADSCs on CS substrates

To examine whether cell culture on CS substrates increased autophagy, the expression of endogenous LC3-II, an autophagosomal marker, was detected by Western blots. ADSCs on TCPS or CS substrates were analyzed at different time points. When grown on CS substrates, the LC3-II protein expression increased from $2 \mathrm{~h}$ and reached a high level at
$8 \mathrm{~h}$. Although the LC3-II protein expression decreased from 16 to $48 \mathrm{~h}$, it was still higher than the starting point (Fig. 1A, right panel). The LC3-II protein expression on TCPS from 4 to $8 \mathrm{~h}$ also slightly increased, but the fold of increase was much lower than that on CS substrates (Fig. 1A, left panel). The formation of LC3 puncta was further examined at $24 \mathrm{~h}$. Formation of GFP-LC3 puncta in ADSCs on CS substrates was clearly observed and the number of GFP-LC3 puncta was more than that on TCPS (Fig. 1B,C). These results indicated that autophagy was more pronounced and prolonged in ADSCs when cultured on CS substrates.

\section{EGTA inhibited autophagy of ADSCs}

on CS substrates

Since the increase in cytosolic $\mathrm{Ca}^{2+}$ could induce autophagy, ${ }^{6,7}$ we sought to investigate whether $\mathrm{Ca}^{2+}$ chelation affected the autophagy of ADSCs on CS substrates. To this end, ADSCs were cultured in the medium containing $0.5-2 \mathrm{mM}$ EGTA (a $\mathrm{Ca}^{2+}$ chelator). After $8 \mathrm{~h}$, the morphology of ADSCs and LC3-II protein expression level were examined. It was observed that $0.5 \mathrm{mM}$ EGTA had no effect on sphere formation, but for concentrations greater than 1-2 mM EGTA the sphere formation was obviously inhibited (Fig. 2A). Western blots showed that when the EGTA concentration increased, the LC3-II protein expression gradually decreased for ADSCs on CS substrates (Fig. 2B). On CS, EGTA at $0.5 \mathrm{mM}$ slightly decreased the LC3-II protein expression of ADSCs. The LC3-II protein expression of ADSCs on CS in the presence of $2 \mathrm{mM}$ EGTA was similar to that on TCPS without EGTA. These results suggested that $\mathrm{Ca}^{2+}$ may be required for the upregulation of ADSC autophagy on CS substrates.

\section{Enhanced cell survival of ADSCs on CS substrates} under oxidative stress may be related to autophagy We hypothesized that the enhanced autophagy in CSderived ADSC spheroids might reduce cell apoptosis under oxidative stress. To mimic the in vivo condition, following cell culture on TCPS for $24 \mathrm{~h}$ or on CS substrates for $72 \mathrm{~h}$, the cells were treated with the medium containing $2 \% \mathrm{FBS}$ and $600 \mu \mathrm{M} \mathrm{H}_{2} \mathrm{O}_{2}$ for $2 \mathrm{~h}$ before the cell viability was assessed. $\mathrm{H}_{2} \mathrm{O}_{2}$ treatment significantly reduced the cell survival of ADSCs grown on TCPS. On the other hand, ADSCs grown on CS substrates showed a higher percentage of cell survival (Fig. 3A). The LC3-II protein expression was also higher for ADSCs grown on CS substrates than on TCPS under 


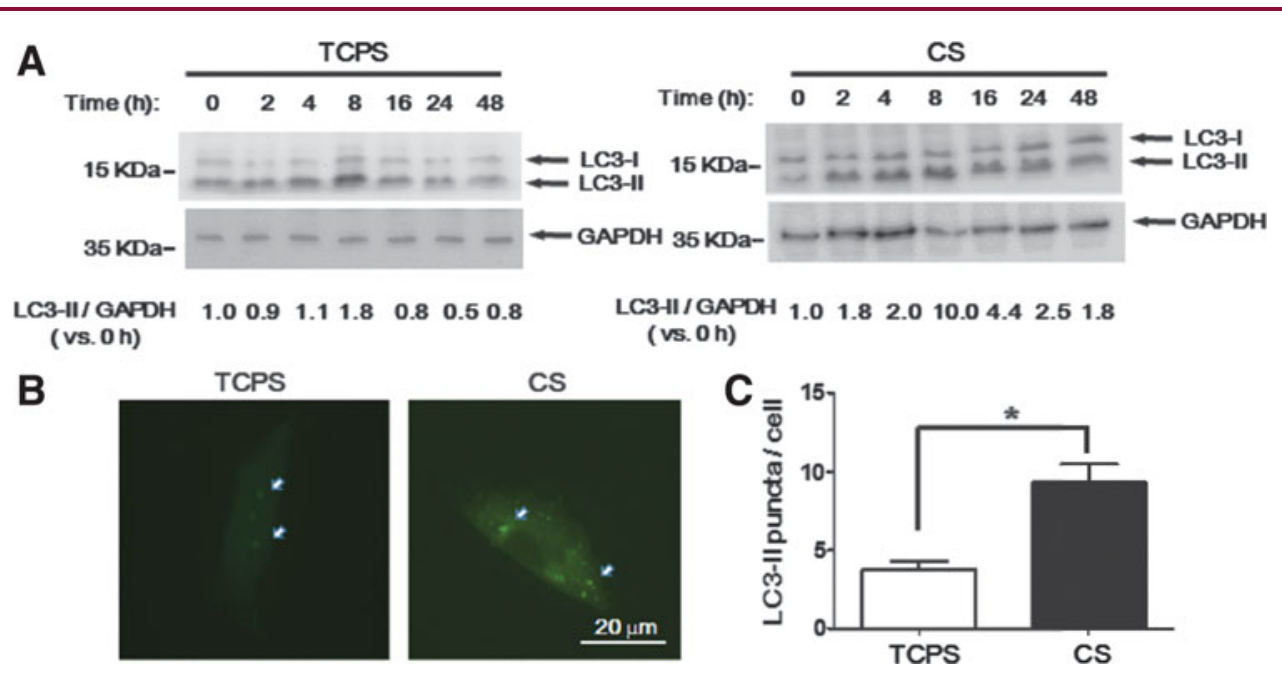

FIG. 1. Upregulation of autophagy in ADSC spheroids. (A) ADSCs were seeded on CS substrates in a 24-well plate or a blank well (TCPS) and harvested at $0,2,4,8,16,24$, and $48 \mathrm{~h}$. The LC3 protein expression was detected by Western blots at the indicated time points. GAPDH was used as an internal control. Band intensities were quantified, and the LC3-II expression was normalized to GAPDH. (B) GFP-LC3 plasmids were transfected to ADSCs and cells were seeded to CS substrates for $24 \mathrm{~h}$. Cells were then transferred to a $1 \%$ gelatin-coated cover slide and fixed. The GFP-LC3 puncta were analyzed with $100 \times$ magnification using a fluorescence microscope. (C) Quantitative analyses of GFP-LC3 puncta per cell. * $p<0.05$ versus TCPS. ADSCs, adipose-derived stem cells; CS, chitosan; TCPS, tissue culture polystyrene.

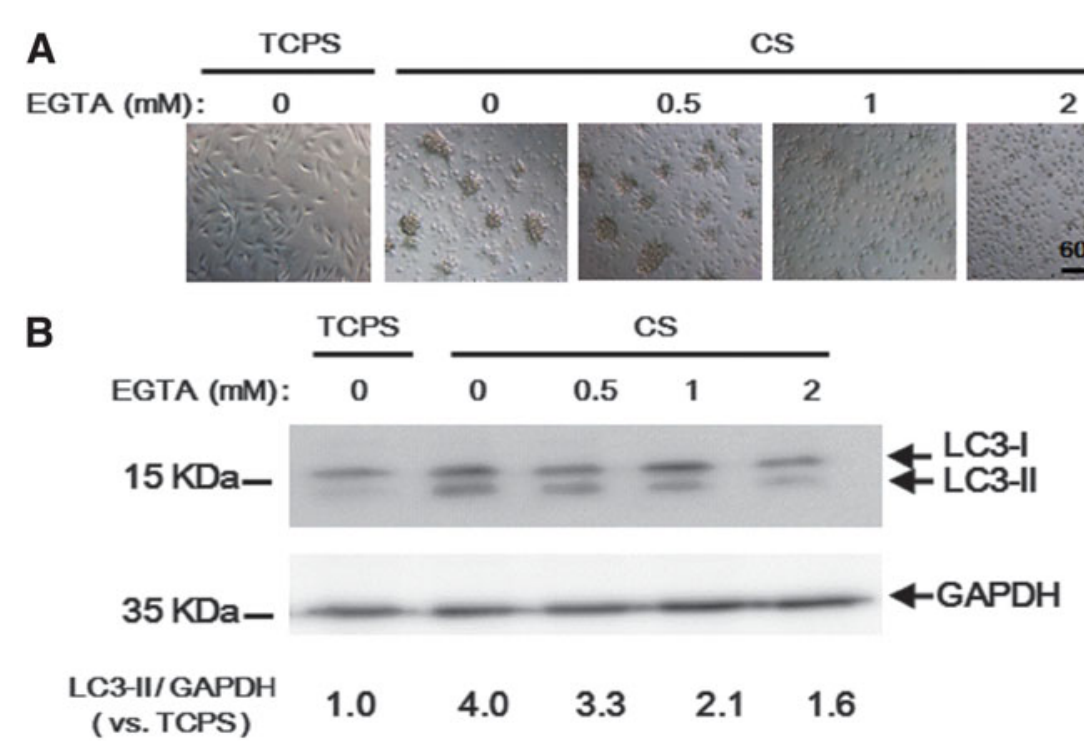

FIG. 2. Autophagy inhibition by EGTA. (A) ADSCs were seeded on CS substrates in a 24-well plate with the medium containing $0,0.5,1$, or $2 \mathrm{mM}$ EGTA or in a blank well (TCPS) for $8 \mathrm{~h}$. The morphologies of ADSCs were taken by the microscope. (B) Cell lysates were collected after treatment and subjected to Western blot analysis with anti-LC3 for LC3-II. GAPDH was used as an internal control. Band intensities were quantified and normalized to GAPDH. EGTA, ethylene glycol tetraacetic acid. 


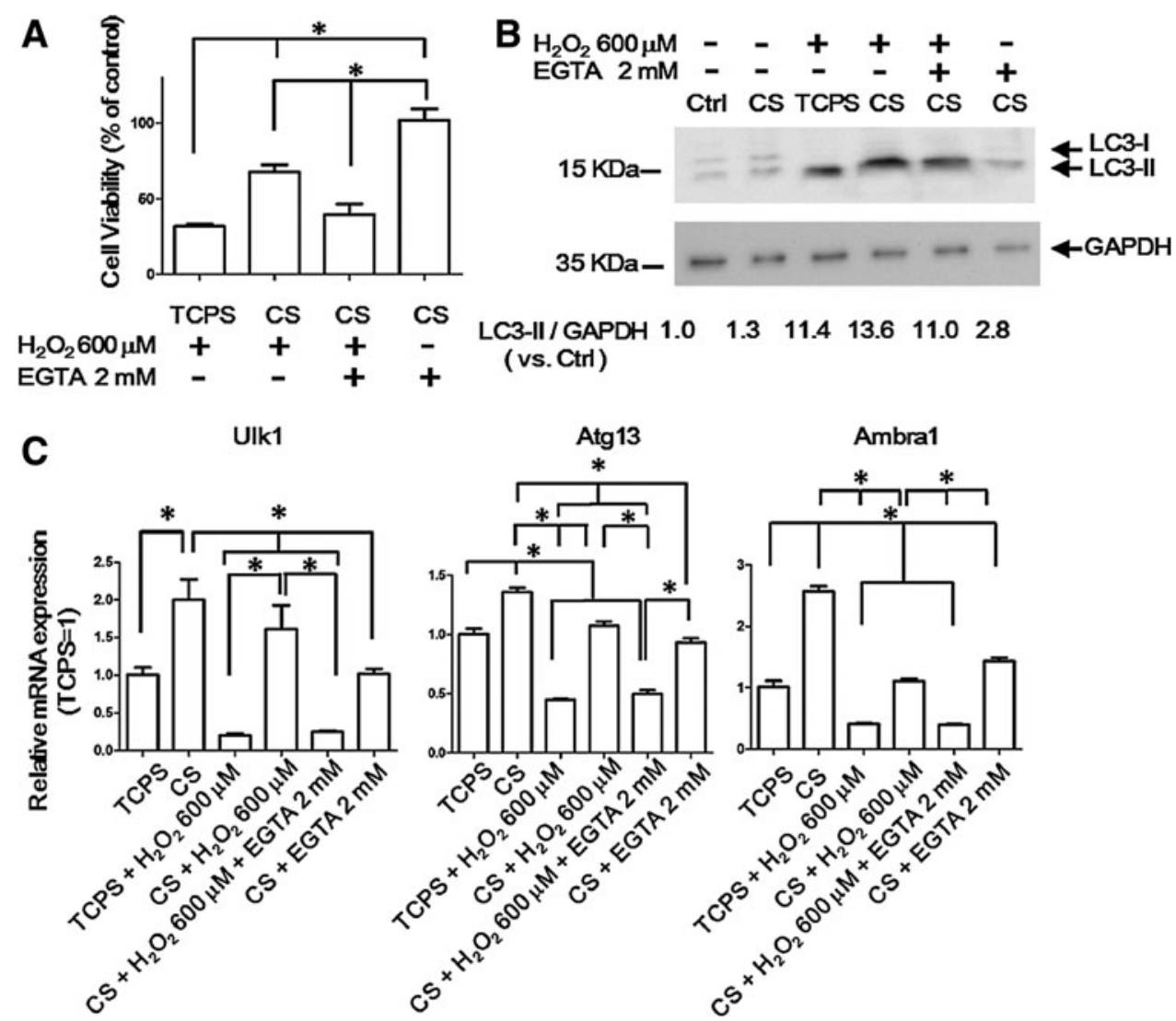

FIG. 3. Autophagy-protecting ADSCs against oxidative stress and low-nutrient condition. (A) Cell viability was estimated by WST-1 assay after $600 \mu \mathrm{M} \mathrm{H}_{2} \mathrm{O}_{2}$ or $2 \mathrm{mM}$ EGTA treatment in $2 \%$ FBS medium for $2 \mathrm{~h} .{ }^{*} p<0.05$. (B) ADSCs were cultured on TCPS for $24 \mathrm{~h}$ or CS $72 \mathrm{~h}$. After treatment as described in (A) for $2 \mathrm{~h}$, cells were harvested and subjected for Western blots with anti-LC3 antibodies. ADSCs grown on TCPS for $24 \mathrm{~h}$ without treatment were defined as the control group (ctrl). Band intensities were quantified and normalized to GAPDH (the internal control). (C) ULk1, Atg13, and Ambra1 mRNA levels were determined by quantitative RT-PCR after treatment as described in (A). ${ }^{*} p<0.05$.

the $\mathrm{H}_{2} \mathrm{O}_{2}$ treatment (Fig. 3B). Furthermore, adding 2 mM EGTA with $\mathrm{H}_{2} \mathrm{O}_{2}$ to the ADSCs grown on CS substrates decreased both the cell viability and LC3II protein expression (Fig. 3A,B). EGTA treatment without $\mathrm{H}_{2} \mathrm{O}_{2}$ for $2 \mathrm{~h}$ presented minor effects to cell viability and LC3-II protein expression for ADSCs grown on CS substrates (Fig. 3A,B). These results implied that the autophagy of CS-derived ADSC spheroids increased and protected them from the oxidative stress and nutrient deprivation in a calcium-dependent manner.

To investigate the possible mechanisms behind the enhanced autophagy of CS-derived ADSC spheroids under the oxidative stress, the mRNA expression of autophagy upstream components was examined. It was noted that Ulk1, Atg13, and Ambral genes were all upregulated for ADSCs grown on CS substrates (Fig. 3C). After $\mathrm{H}_{2} \mathrm{O}_{2}$ treatment, the expression of Ulk1, Atg13, and Ambral mRNA was decreased for both ADSCs cultured on CS substrates and those cultured on TCPS. However, the mRNA expression was still much higher in CS-derived ADSC spheroids (Fig. 3C). EGTA inhibited the mRNA expression of these genes in CS-derived ADSC spheroids under $\mathrm{H}_{2} \mathrm{O}_{2}$ treatment. These results suggested that the enhanced autophagy in CS-derived ADSC spheroids may be 
associated with the upregulation of the autophagy upstream genes Ulk1, Atg13, and Ambra1.

\section{Discussion}

Various in vitro preconditioning methods have been developed to enhance the efficacy of transplanted MSCs. ${ }^{19}$ Hypoxia-induced autophagy can protect MSCs against apoptosis under oxidative stress. ${ }^{11,12}$ MSCs with hypoxic preconditioning significantly improve cell survival after transplantation. ${ }^{20}$ MSC spheroids derived from CS substrates were also shown to have better differentiation capacity and engrafting potential. ${ }^{16,17}$ Our previous study demonstrated that CS-derived ADSC spheroids once transplanted in a chronic myocardial infarction animal model had better therapeutic effects than single cells. ${ }^{17}$ The ischemic area usually exhibits oxidative stress and nutrient deprivation. In this study we demonstrated that autophagy was significantly enhanced in CS-derived ADSC spheroids. Inhibition of autophagy by EGTA treatment decreased the cell viability under the oxidative stress and nutrient deprivation. These results suggested that autophagy may be an important pathway against oxidative stress to enhance the engraftment efficiency for CS-derived MSC spheroids or hypoxia-preconditioned MSCs. Moreover, spermidine and resveratrol that could activate autophagy were used to extend longevity in various model organisms. ${ }^{21-23}$ CS-derived MSC spheroids maintained the expression of stemness marker genes. ${ }^{13} \mathrm{We}$ thus further suggested that the enhanced autophagy in ADSC spheroids may not only protect cells form stress but also prevent early senescence during cell expansion in vitro.

In the current study, the autophagy was induced from 4 to $8 \mathrm{~h}$ when ADSCs were grown on TCPS. On CS substrates, ADSCs revealed a greater autophagy response at each same period, and in particular, the autophagy response was prolonged till $24 \mathrm{~h}$ (Fig. 1A). After $48 \mathrm{~h}$, the autophagy in CS-derived ADSC spheroids returned to nearly the basal level (Fig. 1A). Therefore, it seemed that the CS substrate did not constitutively stimulate the autophagy by itself but rather enhanced the autophagy response. Before $\mathrm{H}_{2} \mathrm{O}_{2}$ treatment, LC3-II protein expression was not increased in ADSCs grown on CS substrates for $72 \mathrm{~h}$ (Fig. 3B). After $\mathrm{H}_{2} \mathrm{O}_{2}$ treatment, the LC3-II protein expression was higher in ADSCs grown on CS substrates than that on TCPS. This result also supported our hypothesis that CS substrates enhanced the autophagy response.
According to the literature, Ulk1, Atg13, and Ambral were kept in an inactive state by mammalian target of rapamycin complex 1 (mTORC1) phosphorylation before stimulation., ${ }^{3,4}$ Upon autophagy induction, mTORC1 is inhibited and Ulk1, Atg13, and Ambral are dephosphorylated and initiate the formation of autophagosomes. ${ }^{3,4}$ In this study, the mRNA expression of components in autophagy-initiating complex increased before $\mathrm{H}_{2} \mathrm{O}_{2}$ treatment in CSderived ADSC spheroids (Fig. 3C). Even after $\mathrm{H}_{2} \mathrm{O}_{2}$ treatment, the mRNA expression of these genes was higher in ADSCs grown on CS substrates than that on TCPS. Based on the above findings, a possible mechanism is depicted (Fig. 4), where higher mRNA expressions of Ulk1, Atg13, and Ambral genes may provide more inactivated autophagy-initiating complex in CS-derived ADSC spheroids, which in turn enhances the autophagy activity upon stimulation (Fig. 4).

The sphere formation of ADSCs on CS substrates was impaired by EGTA treatment (Fig. 2A), as observed in our previous report. ${ }^{24}$ Here we demonstrated that EGTA treatment also inhibited autophagy (Fig. 2B). Autophagy was induced from $2 \mathrm{~h}$ (Fig. 2A), but at this time cells had not aggregated. In another study, inhibition of basal autophagy in glioblastoma stem cells reduced the number of spheres. ${ }^{25}$ Furthermore, we used the low-adherent bacterial Petri dish (Petri dish) to examine the

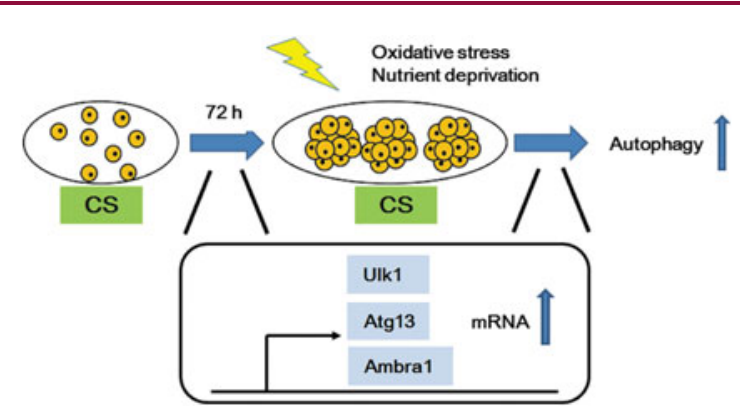

FIG. 4. Possible mechanisms for the enhanced autophagy in ADSCs grown on CS substrates. CS substrates may upregulate Ulk1, Atg13, and Ambra1 mRNA expression. These proteins are inactivated in basal conditions, while upon $\mathrm{H}_{2} \mathrm{O}_{2}$ stimulation, the autophagy-initiating complex may be activated to enhance the autophagy of ADSCs to protect them against oxidative stress. 
correlation between autophagy and spheroid formation. The spheroid formation of ADSCs was observed on Petri dish (Supplementary Data and Supplementary Fig. S1A). The LC3-II level of ADSCs on Petri dish was upregulated 2.5-folds than that in TCPS (Supplementary Fig. S1B). However, the LC3-II level of ADSCs on CS increased fourfolds than that in TCPS (Fig. 2B), and the size of ADSC spheroids on CS was more than that on Perti dish. ${ }^{26}$ These findings indicated that the level of autophagy is associated with the efficiency of spheroid formation.

Mammary epithelial cells grown on poly(2-hydroxyethyl methacrylate) (poly-HEMA)-coated plates detached and aggregated because of extracellular matrix deprivation. $^{27}$ In $3 \mathrm{D}$ epithelial cultures, autophagy was induced to promote epithelial cell survival, but how the loss of integrin engagement may induce autophagy remains unclear. ${ }^{27,28}$ Activation of AMPactivated protein kinase (AMPK) in detached cells was a possible pathway. ${ }^{27}$ LKB1 activation or increase in $\mathrm{Ca}^{2+}$ could activate AMPK and subsequently inhibit mTORC1 to induce autophagy. ${ }^{7}$ Our previous study showed an upregulation of calcium-associated genes in CS-derived MSC spheroids. ${ }^{29}$ CS bound more calcium than TCPS. ${ }^{24}$ Many reports demonstrated that 1,2 bis(o-aminophenoxy)ethane- $N, N, N^{\prime}, N^{\prime}$-tetraaceticacid (BAPTA-AM), a $\mathrm{Ca}^{2+}$ chelator, blocked autophagy. ${ }^{30}$ In the current study, EGTA also decreased autophagy in a dose-dependent manner (Fig. 2B). These results suggested that $\mathrm{Ca}^{2+}$ may play a positive role in the autophagy induction of substrate-derived spheroids.

In conclusion, we found a new method to enhance the stem cell autophagy by $3 \mathrm{D}$ spheroid formation on CS substrates. The induced autophagy may equip MSCs with better survival and therapeutic efficacy once they are transplanted.

\section{Acknowledgments}

We thank Dr. Keng-fu Hsu for providing the GFP-LC3 plasmid. This work was supported by the Program for Stem Cell and Regenerative Medicine Frontier Research (NSC101-2321-B-002-039) sponsored by the National Science Council, Taiwan, ROC.

\section{Author Disclosure Statement}

No competing financial interests exist.

\section{References}

1. Shintani T, Klionsky DJ. Autophagy in health and disease: a double-edged sword. Science. 2004;306:990-995.
2. Mizushima N, Levine B. Autophagy in mammalian development and differentiation. Nat Cell Biol. 2010;12:823-830.

3. Tanida I. Autophagy basics. Microbiol Immunol. 2011;55:1-11.

4. Nazio F, Strappazzon F, Antonioli M, et al. mTOR inhibits autophagy by controlling ULK1 ubiquitylation, self-association and function through AMBRA1 and TRAF6. Nat Cell Biol. 2013;15:406-416.

5. Kabeya Y, Mizushima N, Ueno T, et al. LC3, a mammalian homologue of yeast Apg8p, is localized in autophagosome membranes after processing. EMBO J. 2000;19:5720-5728

6. Ghislat G, Patron M, Rizzuto R, et al. Withdrawal of essential amino acids increases autophagy by a pathway involving $\mathrm{Ca}^{2+} /$ calmodulindependent kinase kinase- $\beta$ (CaMKK- $\beta$ ). J Biol Chem. 2012;287: 38625-38636.

7. Kondratskyi A, Yassine M, Kondratska K, et al. Calcium-permeable ion channels in control of autophagy and cancer. Front Physiol. 2013;4:272.

8. Lotfinegad P, Shamsasenjan K, Movassaghpour A, et al. Immunomodulatory nature and site specific affinity of mesenchymal stem cells: a hope in cell therapy. Adv Pharm Bull. 2014;4:5-13.

9. Mastri M, Lin H, Lee T. Enhancing the efficacy of mesenchymal stem cel therapy. World J Stem Cells. 2014;6:82-93.

10. Herberg $\mathrm{S}$, Shi $\mathrm{X}$, Johnson $\mathrm{MH}$, et al. Stromal cell-derived factor- $1 \beta$ mediates cell survival through enhancing autophagy in bone marrow-derived mesenchymal stem cells. PLoS One. 2013;8:e58207.

11. Zhang $\mathrm{Q}$, Yang YJ, Wang $\mathrm{H}$, et al. Autophagy activation: a novel mechanism of atorvastatin to protect mesenchymal stem cells from hypoxia and serum deprivation via AMP-activated protein kinase/mammalian target of rapamycin pathway. Stem Cells Dev. 2012;21:1321-1332.

12. Wang L, Hu X, Zhu W, et al. Increased leptin by hypoxic-preconditioning promotes autophagy of mesenchymal stem cells and protects them from apoptosis. Sci China Life Sci. 2014;57:171-180.

13. Huang GS, Dai LG, Yen BL, et al. Spheroid formation of mesenchymal stem cells on chitosan and chitosan-hyaluronan membranes. Biomaterials. 2011;32:6929-6945.

14. Hsu SH, Huang GS, Feng F. Isolation of the multipotent MSC subpopulation from human gingival fibroblasts by culturing on chitosan membranes. Biomaterials. 2012;33:2642-2655.

15. Hsu SH, Huang GS. Substrate-dependent Wnt signaling in MSC differentiation within biomaterial-derived 3D spheroids. Biomaterials. 2013;34:4725-4738.

16. Tseng TC, Hsu SH. Substrate-mediated nanoparticle/gene delivery to MSC spheroids and their applications in peripheral nerve regeneration. Biomaterials. 2014;35:2630-2641.

17. Liu BH, Yeh HY, Lin YC, et al. Spheroid formation and enhanced cardiomyogenic potential of adipose-derived stem cells grown on chitosan. Biores Open Access. 2013;2:28-39.

18. Livak KJ, Schmittgen TD. Analysis of relative gene expression data using real-time quantitative PCR and the 2(-Delta Delta $C(T)$ ) Method. Methods. 2001;25:402-408.

19. Sart S, Ma T, Li Y. Preconditioning stem cells for in vivo delivery. Biores Open Access. 2014:3:137-149.

20. Haque N, Rahman MT, Abu Kasim NH, et al. Hypoxic culture conditions as a solution for mesenchymal stem cell based regenerative therapy. ScientificWorldJournal. 2013:632972.

21. Eisenberg $\mathrm{T}$, Knauer $\mathrm{H}$, Schauer $\mathrm{A}$, et al. Induction of autophagy by spermidine promotes longevity. Nat Cell Biol. 2009;11:1305-1314.

22. Howitz KT, Bitterman KJ, Cohen HY, et al. Small molecule activators of sirtuins extend Saccharomyces cerevisiae lifespan. Nature. 2003;425:191196.

23. Wood JG, Rogina B, Lavu S, et al. Sirtuin activators mimic caloric restriction and delay ageing in metazoans. Nature. 2004;430:686-689.

24. Yeh HY, Liu BH, Hsu SH. The calcium-dependent regulation of spheroid formation and cardiomyogenic differentiation for MSCs on chitosan membranes. Biomaterials. 2012;33:8943-8954.

25. Filippi-Chiela EC, Villodre ES, Zamin LL, et al. Autophagy interplay with apoptosis and cell cycle regulation in the growth inhibiting effect of resveratrol in glioma cells. PLoS One. 2011;6:e20849.

26. Huang GS, Hsieh PS, Tseng CS, et al. The substrate-dependent regeneration capacity of mesenchymal stem cell spheroids derived on various biomaterial surfaces. Biomater Sci. 2014:2:1652-1660.

27. Fung $C$, Lock $R$, Gao $S$, et al. Induction of autophagy during extracellular matrix detachment promotes cell survival. Mol Biol Cell. 2008;19: 797-806. 
28. Lock R, Debnath J. Extracellular matrix regulation of autophagy. Curr Opin Cell Biol. 2008;20:583-588.

29. Yeh HY, Liu BH, Sieber M, et al. Substrate-dependent gene regulation of self-assembled human MSC spheroids on chitosan membranes. BMC Genomics. 2014;15:10.

30. Decuypere JP, Bultynck G, Parys JB. A dual role for $\mathrm{Ca}(2+)$ in autophagy regulation. Cell Calcium. 2011;50:242-250.

Cite this article as: Yang CM, Huang YJ, Hsu SH (2015) Enhanced autophagy of adipose-derived stem cells grown on chitosan substrates, BioResearch Open Access 4:1, 89-96, DOI: 10.1089/ biores.2014.0032.

$\begin{aligned} & \text { Abbreviations Used } \\ 3 \mathrm{D} & =\text { three-dimensional } \\ \mathrm{ADSC} & =\text { adipose-derived stem cells } \\ \mathrm{Ambra} 1 & =\text { autophagy/beclin- } 1 \text { regulator } 1 \\ \mathrm{AMPK} & =\text { AMP-activated protein kinase } \\ \mathrm{Atg} 13 & =\text { autophagy-related protein } 13 \\ \mathrm{CS} & =\text { chitosan } \\ \mathrm{EGTA} & =\text { ethylene glycol tetraacetic acid } \\ \mathrm{FBS} & =\text { fetal bovine serum } \\ \mathrm{LC} 3 & =\text { microtubule-associated protein } 1 \text { light chain } 3 \\ \mathrm{MSCs} & =\text { mesenchymal stem cells } \\ \mathrm{mTORC1} & =\text { mammalian target of rapamycin complex } 1 \\ \mathrm{TCPS} & =\text { tissue culture polystyrene } \\ \mathrm{Ulk} 1 & =\text { UNC51-like kinase } 1\end{aligned}$

\section{Publish in BioResearch Open Access}

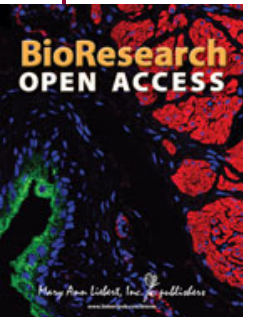

- Broad coverage of biomedical research - Immediate, unrestricted online access - Rigorous peer review - Compliance with open access mandates - Authors retain copyright

- Highly indexed

- Targeted email marketing

\section{liebertpub.com/biores}

